\title{
Stress distributions of PSC box girder bridge due to creep shrinkage effect
}

\author{
Baskoro Abdi Praja ${ }^{1}$ \\ ${ }^{1}$ Civil Eng. Department of Universitas Atma Jaya, 44 Babarsari, Yogyakarta Special District, \\ Indonesia
}

\begin{abstract}
Long-span bridges are usually designed with a service life of more than 20 years. Thus, it is required to consider factors that are affected by time. Creep and shrinkage are parameters to predict time-dependent behavior of a bridge. The purpose of this study is to determine the effects of creep \& shrinkage toward total stresess. Lemah Ireng 1 Bridge in Semarang-Solo toll road was used as a case study. The bridge has a total span length of $879 \mathrm{~m}$. It has a service life design of 100 years. Therefore, this creep and shrinkage research is necessary to determine the stress distribution in the box girder bridge until the end of the service life. Computational modelling was conducted to estimate the stress distribution in the structure of the box girder bridge. Several stages of loading on the bridges were applying asphalt leveling, barrier, creep and shrinkage load by using a variation of the long-term duration with intervals of $5,10,15$, 20, 40, 60, 80 and 100 years. The analysis was using linear static method, Construction Stage Analysis-Time Dependent effects on Midas Civil and only apply non-transient load on the bridge structure. This study is expected to show the impact of the creep and shrinkage effects of the total stresses along the bridge span until the service life of 100 years.
\end{abstract}

\section{Background}

Lemah Ireng 1 Bridge (LI1) is a prestressed concrete box girder bridge with a total length of $879 \mathrm{~m}$ that uses Free Cantilever Method (FCM) as in Figure 1. In the construction stage, there were two changes of technical conditions. The changes are described as sand material changes density of concrete up to $26 \mathrm{kN} / \mathrm{m}^{3}$ and changes of moving traveller schedule. Both changes make a difference on the precamber value. The condition allegedly causes the difference between the designed elevation and the actual elevation so that requires asphalt leveling which vary in size. It has a service life design of 100 years, but based on the actual conditions that occured, it is necessary to review the performances and the strength of longterm serviceability. Praja (2016) has performed a deflection analysis for 100 years. This study reviewed the stress distribution along the span at the age of 100 years. 


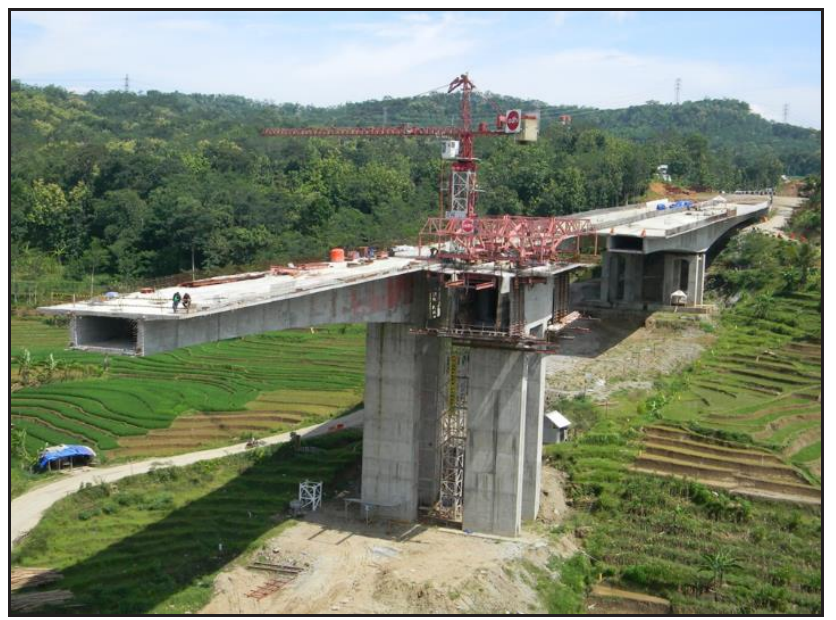

Fig. 1. Construction of PSC box girder bridge using free cantilever method. (Adhi Karya Corporation, 2013)

\section{Literature review}

Pan et al (2011) analyzed the long-term behavior of a long-span PSC box girder bridge. The study compared the results of stress measurements toward modified creep and shrinkage models. The deviations of stress of the top is $1.7 \mathrm{MPa}$ and the greatest deviation of $2.2 \mathrm{MPa}$ occurs in casting the 18 \# segment. The deviation of stress of the bottom slab between calculated values and measured values is around $1.2 \mathrm{MPa}$ and the greatest deviation of 1.75 $\mathrm{MPa}$ occurs in casting the $18 \#$ segment.

Bao et al (2015) conducted a study on the impact of shrinkage on the box girder bridge. This study shows the effect of shrinkage on the stress along the span. Creep and shrinkage in concrete show a great impact on the internal forces. After 3 years of completion, the results showed that the effects of creep and shrinkage are 1.9 MPa and 0.78 MPa in upper and bottom flange as compressive stress. By considering the shrinkage and creep near the bridge pier, the bridge stress decreased by $15.4 \%$ at the maximum; while near the midspan, the stress maximally increased by $7.3 \%$.

The effects of creep and shrinkage can be fatal if neglected; so it becomes the primary object of the study of Lemah Ireng 1 Bridge. By considering the effects of long-term stresses, it is necessary to conduct a research on the performance of Lemah Ireng 1 Bridge.

\section{The theoritical calculations of the concrete creep and shrinkage}

In normal concrete structures, the continuous dead load causes a creep (Analysis Reference of Midas Civil, 2011). If a unit axial stress $\sigma=1$ in a concrete type with the age of $t_{0}$, then the axial strain result at age $t$ is defined as $J\left(t, t_{0}\right)$.

$$
\varepsilon(t)=\varepsilon_{i}\left(t_{0}\right)+\varepsilon_{c}\left(t, t_{0}\right)=\sigma . J\left(t, t_{0}\right)
$$


$J\left(t, t_{0}\right)$ represents the total that occurs in the unit of stress and is defined as the creep function. Figure 2 shows that the $J\left(t, t_{0}\right)$ creep function can be represented by the initial number of elastic strain and the creep strain as follows:

$$
J\left(t, t_{0}\right)=\frac{1}{E\left(t_{0}\right)}+C\left(t, t_{0}\right)
$$

$E\left(t_{0}\right)$ represents the modulus of elasticity when the load is applied, and $C\left(t, t_{0}\right)$ represents the resulting deformation creep at the age of $t$, which is referred to as the specified creep.
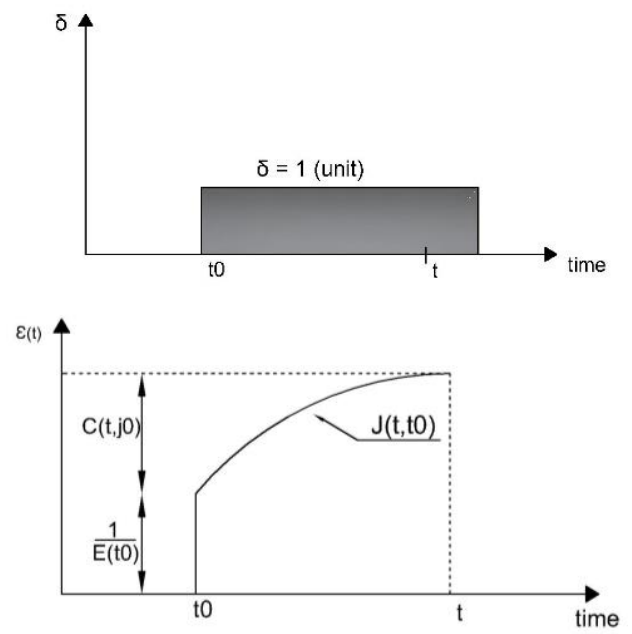

Fig. 2. The definition of the creep and specific creep function (Analysis Reference of Midas Civil,2011)

The creep function $J\left(t, t_{0}\right)$ can also be expressed in a relative comparison to elastic deformation

$$
J(t, t 0)=\frac{1+\phi(t, t 0)}{E(t 0)}
$$

$\phi(t, t 0)$ is defined as the creep coefficient which represents the creep ratio to elastic deformation. The specific creep can also be expressed as follows:

$$
\begin{aligned}
& \phi\left(t, t_{0}\right)=E\left(t_{0}\right) \cdot C\left(t, t_{0}\right) \\
& C\left(t, t_{0}\right)=\frac{\phi\left(t, t_{0}\right)}{E\left(t_{0}\right)}
\end{aligned}
$$

Midas Civil allows determining the coefficient of creep and shrinkage calculated by the CEB-FIP, ACI, and others or can also be directly determined by the values obtained from the experiment.

Shrinkage is a function of time that is free of pressure in a concrete element. Strain due to shrinkage is usually expressed by time from $t_{0}$ to $t$. 


$$
\varepsilon_{s}\left(t, t_{0}\right)=\varepsilon_{s 0} \cdot f\left(t, t_{0}\right)
$$

Where $\varepsilon_{s 0}$ represents the shrinkage coefficient at the end time, $f\left(t, t_{0}\right)$ is the time function, $t$ is the observation time and $t_{0}$ is the initial shrinkage time.

\section{Engineering Background}

Lemah Ireng 1 Bridge has a span of $879 \mathrm{~m}$ with a configuration of $72+115.5+120+136$ $+136+120+74.5+50 \mathrm{~m}$ as the main span and $18+19+18 \mathrm{~m}$ as the approach span. The pier height varies from $4 \mathrm{~m}$ to $44.5 \mathrm{~m}$. The type of deck on the bridge is cast in situprestressed concrete box. The total width of the deck is $2 \times 12.6 \mathrm{~m}$. The height of the deck varies from $3 \mathrm{~m}$ to $6.5 \mathrm{~m}$ as in Figure 3 and 4 . The used construction method is Balance Cantilever - Form Traveller.

There were special conditions occured in the construction. First, changes in the material used in the actual condition of the existing type of concrete weight were greater than the deflection analysis,thus the weight itself become larger as the consequences. The concrete compressive strength was increased from the planned 41.5 $\mathrm{MPa}$ to $55.51 \mathrm{MPa}$. Second, there was a change in the sequence of construction methods in the field which is the change of traveller movement due to land acquisition problems as in Figure 5 and 6, so that the precamber was not in accordance with actual conditions that occured.

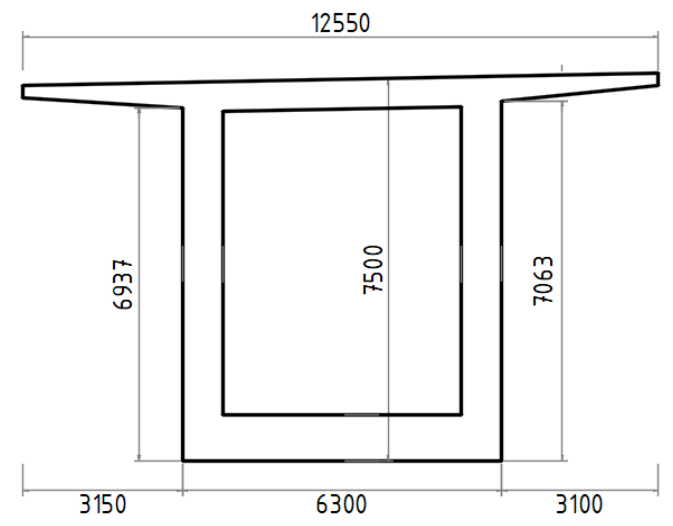

Fig. 3. Girder cross sections at piers 4 in milimeters.

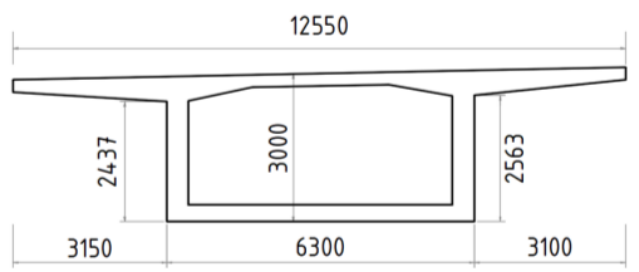

Fig. 4. Girder cross sections at midspan in milimeters. 


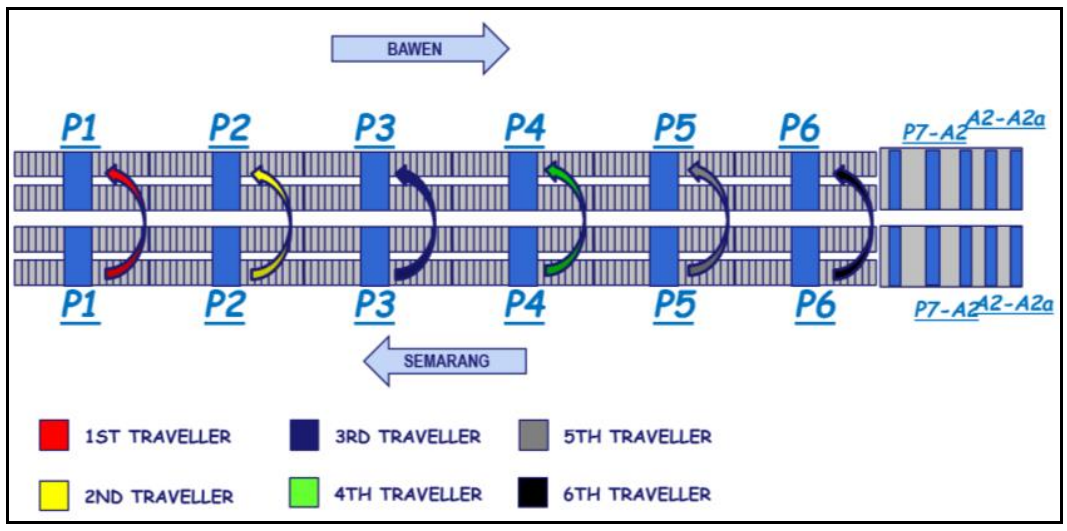

Fig. 5. Plan design of traveller movements. (Adhi Karya Corporation, 2013).

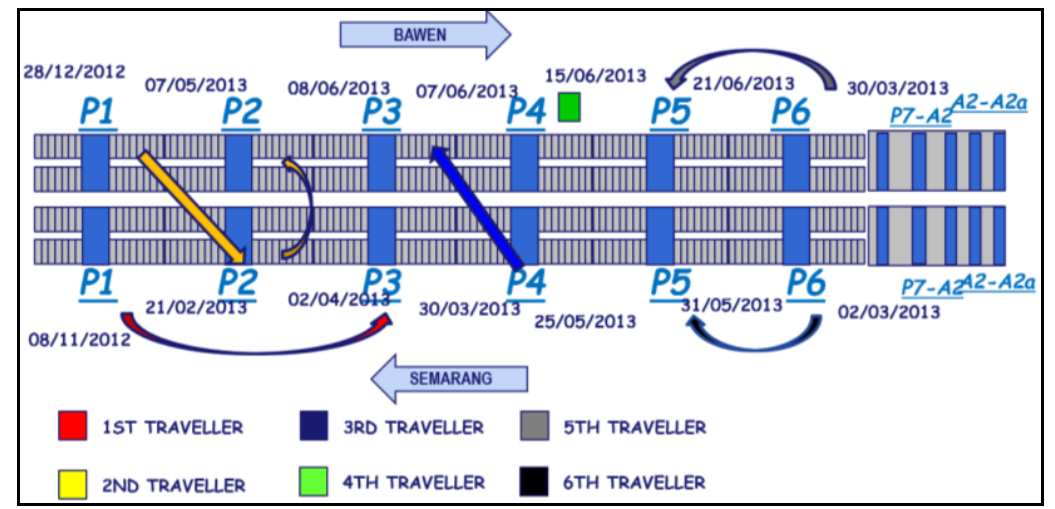

Fig. 6. Actual traveller movements. (Adhi Karya Corporation, 2013).

\section{Research methods}

The study is based on the analysis of Construction Stage with Civil Midas 2011 Evaluation Licensed. LI1 bridge structure is modeled as a 3D frame element of box girder balanced cantilever method as overall as shown in Figure 7. Some idealizations of the modeling of box girder bridge and its pillars are modeled as frame elements; pedestal structure modeled joints on the bearing pad in abutment; connections with the pillar box girder is modeled with elastic link rigid type; pedestal pillar modeled as fixed.

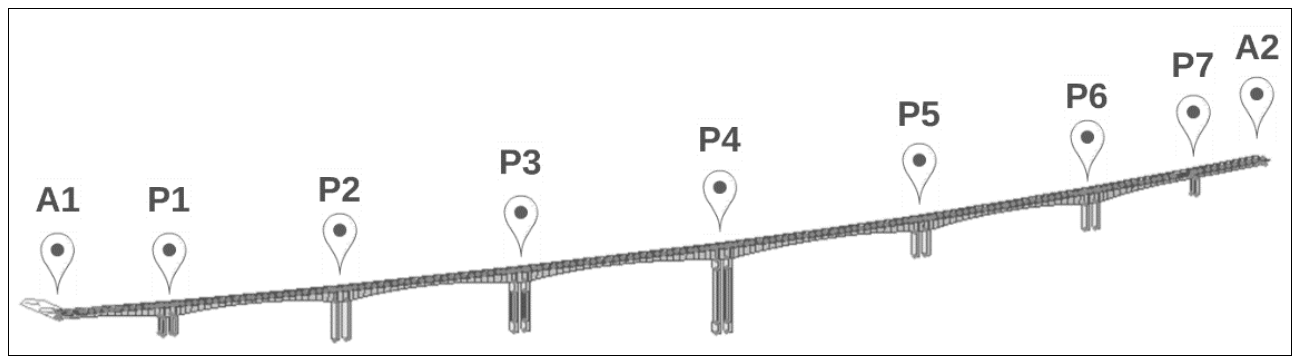

Fig. 7. LI1 Bridge finite element model. 
The loading on the construction stage includes the following:

a. Weight of the structure.

b. Prestressed tendons load.

c. Traveller load and wet concrete load. Load of $650 \mathrm{KN}$ traveller form and weight of wet material idealized as a point load in the form of vertical force in the direction of gravity and the moment due to the eccentricity of the vertical force of $0.5 \mathrm{Ls}$ (half length of segment).

d. Live Load during construction is idealized as a uniform load of $2 \mathrm{KN} / \mathrm{m}^{2}$.

e. Additional dead load by inserting a barrier which is modeled as a distributed load.

f. Asphalt load is modeled as a distributed load with a unit weight of $22 \mathrm{KN} / \mathrm{m}^{3}$.

g. Creep and shrinkage load to100 years.

The analysis of the long-term creep and shrinkage uses the standard of CEB-FIP 1990. The bridge structure was analyzed in a linear static. Construction Stage Analysis in Civil Midas software is used as a media to acknowledge the time-dependent effects. The analysis was carried out based on the condition of the bridge that has been deformed by the construction phase. Praja et al (2016) obtained the span of P4-P5 that has maximum deflection, so this paper only has a review on P4-P5 span. This study compared the design toward actual conditions as in Table 1 . In this study, the time span bridge was taken at age $5,10,15,20,40,60,80$ and 100 years.

Table 1. Comparison on input of bridge model properties and load.

\begin{tabular}{|c|c|c|c|}
\hline $\begin{array}{c}\text { No } \\
\cdot\end{array}$ & Subject of differences & Design Model & Actual Model \\
\hline 1 & Age of Concrete at the Beginning of Shrinkage & 3 rd day & 1 st day \\
\hline 2 & Compressive Strength & $41.5 \mathrm{Mpa}$ & $55.51 \mathrm{Mpa}$ \\
\hline 3 & Weight Density of Pier & $24 \mathrm{KN} / \mathrm{m}^{3}$ & $26 \mathrm{KN} / \mathrm{m}^{3}$ \\
\hline 4 & Weight Density of Box Girder & $25 \mathrm{KN} / \mathrm{m}^{3}$ & $26 \mathrm{KN} / \mathrm{m}^{3}$ \\
\hline 5 & Asphalt Levelling & max. $5 \mathrm{~cm}$ & max. $20 \mathrm{~cm}$ \\
\hline 6 & Construction Stage & Design Sequence & Actual Sequence \\
\hline
\end{tabular}

\section{Long-Term Stresses}

Long-term loading depends on the effect of time. It changes the internal force, so it can change the stresses on each girder cross section. Creep and shrinkage are time-dependent factors. The diagram shown is a 100-year stress analysis.

In Figure 8, the stress distribution due to creeps and shrinkages on the upper flange shows a tensile - compressive (midspan) - tensile distribution along the span with a maximum tensile stress of $6.615 \mathrm{MPa}$ and a compressive stress of $1.5285 \mathrm{MPa}$. The effect of shrinkage on 100 years after construction is $26 \%$ at most. 


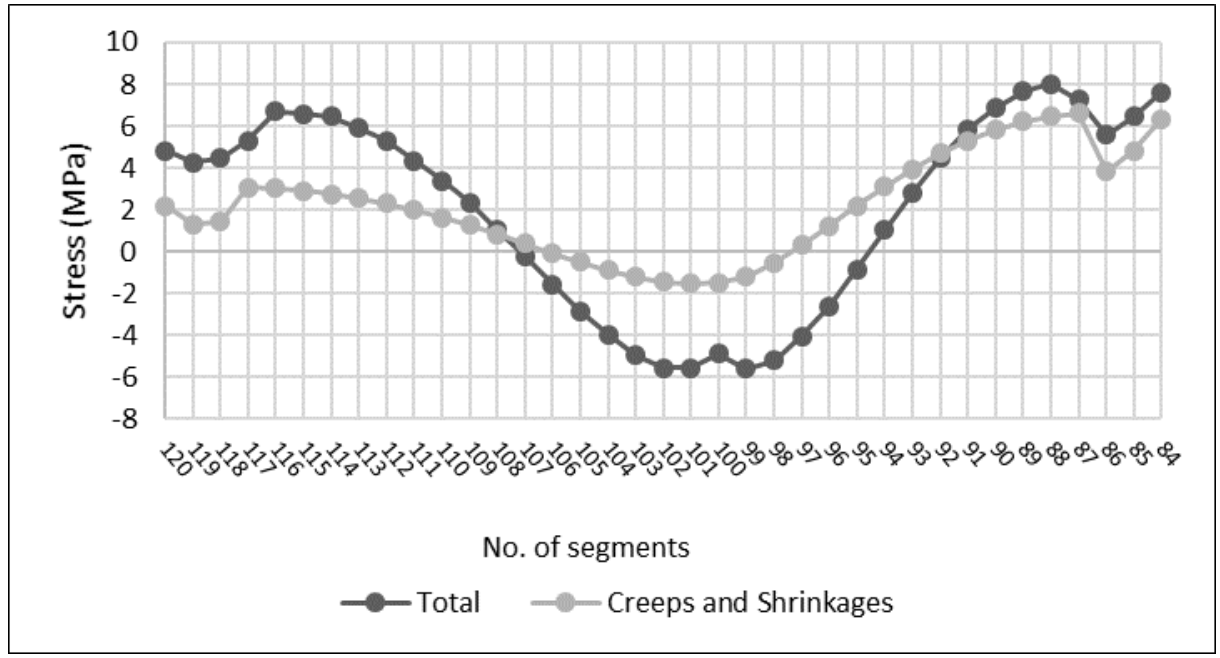

Fig. 8. Stress distribution at upper flange of girder at span P4-P5 (design).

In Figure 9, the stress distribution due to creeps and shrinkages on the bottom side shows a compressive - tensile (midspan) - compressive distribution along the span with a maximum tensile stress of $10.6644 \mathrm{MPa}$ and a compressive stress of $1.1938 \mathrm{MPa}$. The effect of shrinkage on 100 years after construction is $10 \%$ at most.

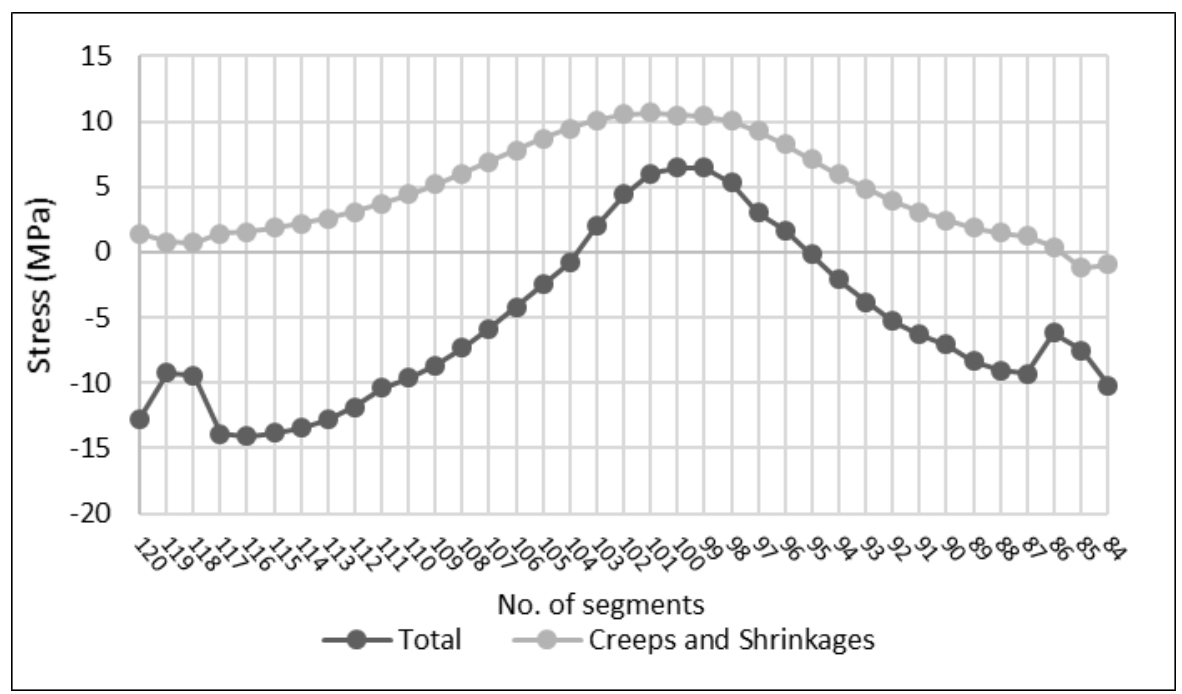

Fig. 9. Stress distribution at bottom side of girder at span P4-P5 (design).

In Figure 10, the stress distribution due to creeps and shrinkages on the upper flange shows a tensile - compressive (midspan) - tensile distribution along the span with a maximum tensile stress of 5.0977 MPa and a compressive stress of 1.4021 MPa. The effect of shrinkage on 100 years after construction is $21 \%$ at most. 


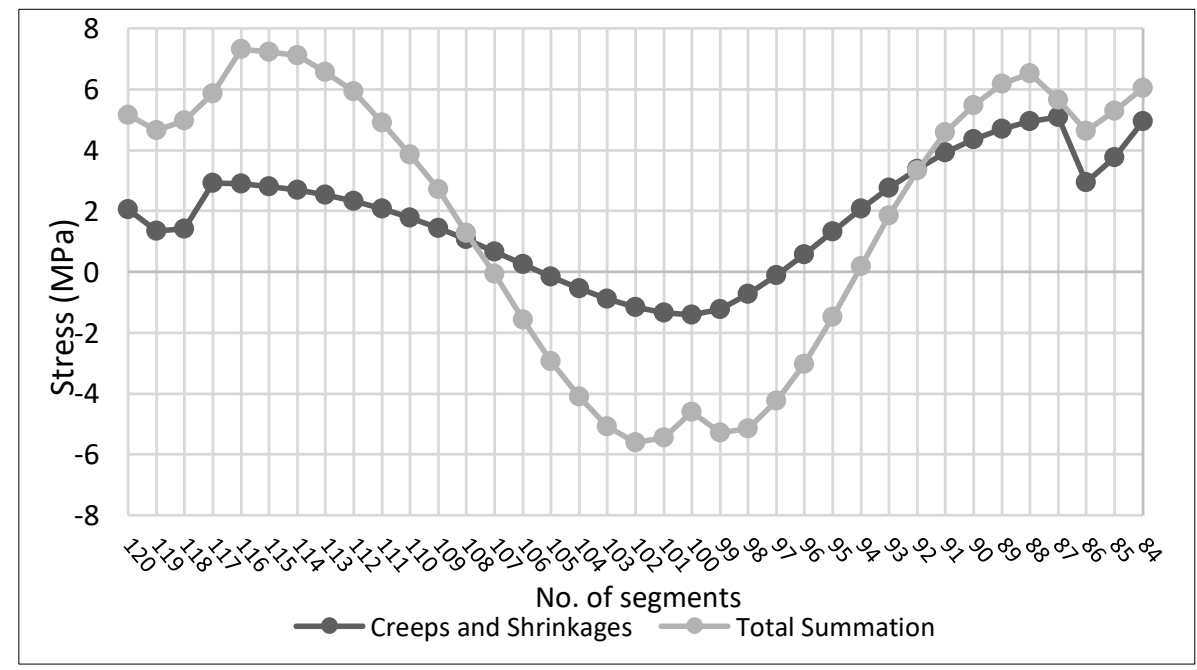

Fig. 10. Stress distribution at upper flange of girder at span P4-P5 (actual).

In Figure 11, the stress distribution due to creeps and shrinkages on the bottom side shows a compressive - tensile (midspan) - compressive distribution along the span with a maximum tensile stress of $8.9655 \mathrm{MPa}$ and a compressive stress of $0.734 \mathrm{MPa}$. The effect of shrinkage on 100 years after construction is $6 \%$ at most.

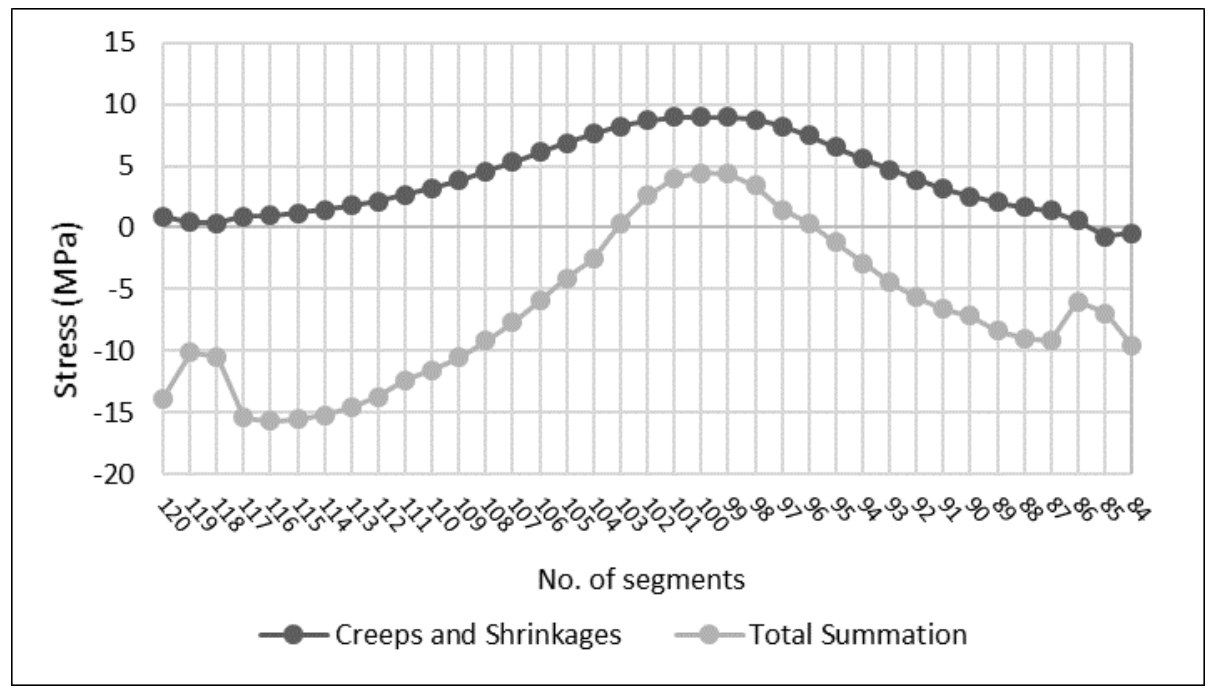

Fig. 11. Stress distribution at bottom side of girder at span P4-P5 (actual).

In Figure 12, the highest deviation of tensile stress between actual and design is in segment 88 . Stresses on the segment shows that the tensile stress of the design is greater than the actual tensile stress. In the middle of the span, the compressive stress between the actual tensile stress and the design is quite the same. 


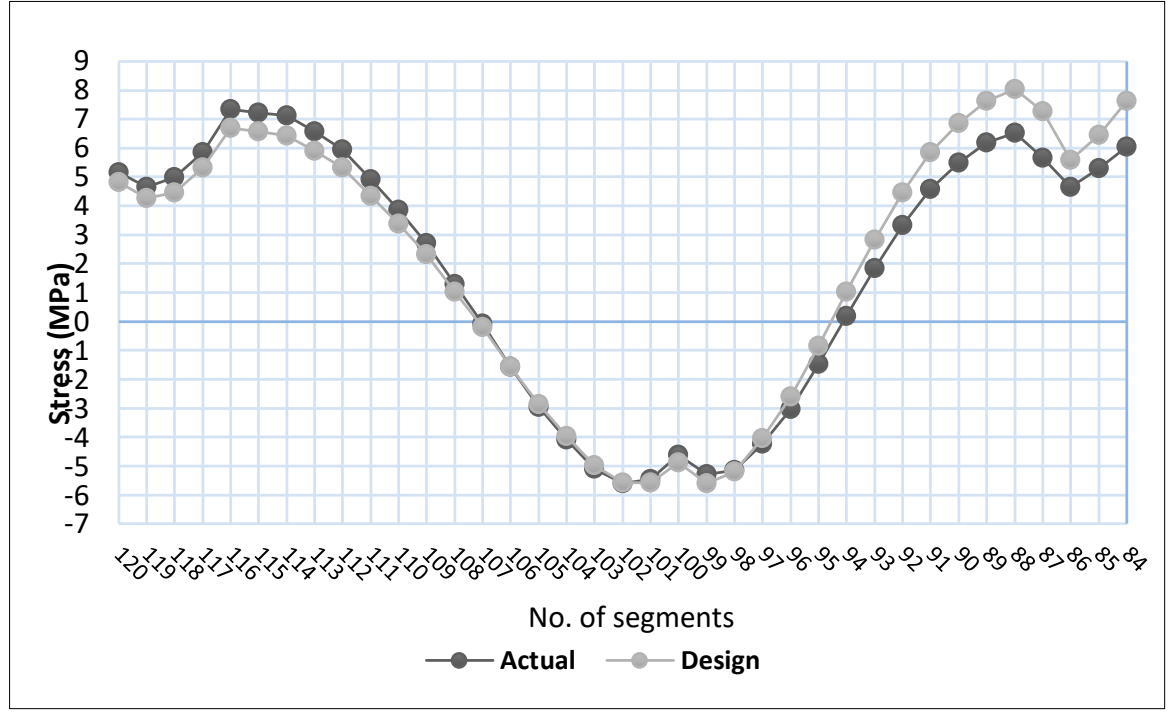

Fig. 12. Total Stress distribution at upper flange of girder at span P4-P5.

In Figure 13, the highest deviation of tensile stress between actual and design is in segment 100. Stresses on the segment show that the tensile stress of the design is greater than the actual tensile stress. Highest deviation of compressive stress occurs on segment 116. Stresses on the segment shows that the compressive stress of the design is smaller than the actual tensile stress.

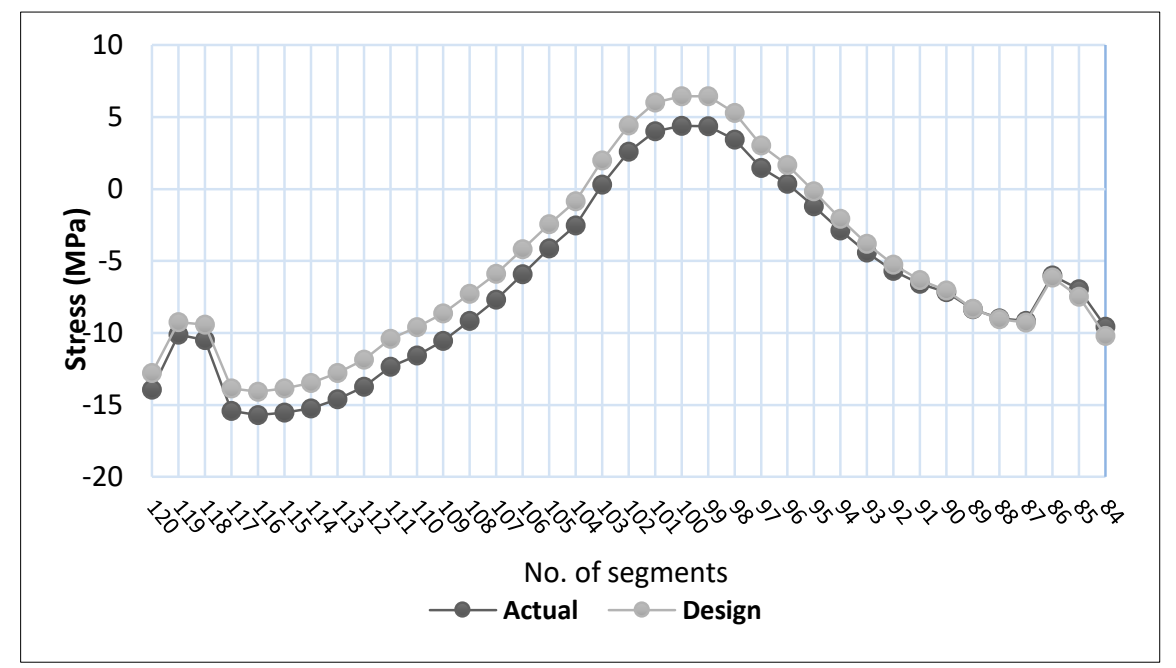

Fig. 13. Total Stress distribution at Bottom side of girder at span P4-P5.

\section{Conclusion}

Based on the research that has been done, it can be concluded as follows:

a. The actual model has a smaller creep and shrinkage effect than the designed model. The maximum tensile stress due to the effect of creep and shrinkage is 10,644 MPa 
below the designed model. The maximum compressive stress due to the effect of creep and shrinkage is $1.5285 \mathrm{Mpa}$.

b. The top section has stress distribution as tensile-compressive(midspan)-tensile. The bottom side of the sections has a stress distribution as compressive-tensilecompressive.

\section{References}

1. Adhi Karya Corporation, Innovation Paper (2013)

2. Bao, L., Li, G., Yu, L., Zhu, G., 'Impact Analysis of Concrete Shrinkage and Creep on a Prestressed Concrete Box Girder Bridge", ICTE (2015)

3. Comité Euro-International du Béton (CEB), CEB-FIP model code 1990 (1990)

4. Midas Civil, Analysis Reference, Midas User Support System (2011)

5. Pan, Z., Fu. C. C., Jiang, Y., "Uncertainty Analysis of Creep and Shrinkage Effects in Long-Span Continuous Rigid Frame of Sutong Bridge, J. Bridge Eng”, 16, 248-258 (2011)

6. Praja, B.A.,Triwiyono, A., Perilaku Rangkak Susut Terhadap Lendutan Struktur Jembatan Bentang Panjang, DOI: 10.24002/jts.v13i4.934 (In Indonesian), (2016) 